Supporting information for the manuscript entitled

\title{
The Impact of Drug-Polymer Intermolecular Interactions on Dissolution Performance of Copovidone-Based Amorphous Solid Dispersions
}

Chailu Que, ${ }^{1}$ Alexandru Deac, ${ }^{1}$ Dmitry Y. Zemlyanov, ${ }^{2}$ QingQing Qi, ${ }^{3}$ Anura S. Indulkar, ${ }^{4}$ Yi Gao, ${ }^{5}$ Geoff G. Z. Zhang, ${ }^{4}$ and Lynne S. Taylor ${ }^{1}$

1. Department of Industrial and Physical Pharmacy, College of Pharmacy, Purdue University, West Lafayette, Indiana 47907, United States

2. Birck Nanotechnology Center, Purdue University, West Lafayette, Indiana 47907, United States

3. Department of Chemistry, College of Science, Purdue University, West Lafayette, Indiana 47907, United States

4. Drug Product Development, Research and Development, AbbVie Inc., North Chicago, Illinois 60064, United States

5. Science and Technology, Operations, AbbVie Inc., North Chicago, Illinois 60064, United States

Correspondence to: Geoff G.Z. Zhang (Telephone: +1-847-937-4702; Fax: +1-847-

937-7756) and Lynne S. Taylor (Telephone: +1-765-496-6614; Fax: +1-765-494$6545)$. 
E-mail addresses: Geoff.GZ.Zhang@abbvie.com (G.G.Z. Zhang), 1staylor@purdue.edu(L.S.

Taylor)

\section{Synthesis of 3,3-bis(4-methoxyphenyl)isobenzofuran-1(3H)-one (Me-PHPH)}<smiles>O=C1OC(c2ccc(O)cc2)(c2ccc(O)cc2)c2ccccc21</smiles>

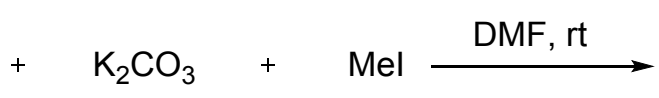<smiles>COc1ccc(C2(c3ccc(OC)cc3)OC(=O)c3ccccc32)cc1</smiles>

To a solution of 3,3-bis(4-hydroxyphenyl)isobenzofuran-1(3H)-one (9.6 g, $30.0 \mathrm{mmol}, 1.0$ equiv) in anhydrous DMF $(50 \mathrm{~mL})$ at $\mathrm{rt}$ under Argon was added $\mathrm{K}_{2} \mathrm{CO}_{3}(16.6 \mathrm{~g}, 120.0 \mathrm{mmol}, 4.0$ equiv) and $\mathrm{MeI}(9.4 \mathrm{~mL}, 150.0 \mathrm{mmol}, 5.0$ equiv) via a syringe. The reaction mixture was stirred overnight. The mixture was poured into water and extracted with DCM for three times. The combined organic phase were washed with brine, dried over $\mathrm{Na}_{2} \mathrm{SO}_{4}$, concentrated to afford the title products as yellow thick oil $(10.0 \mathrm{~g}, 96.2 \%)$.

${ }^{1} \mathrm{H}$ NMR (800 MHz, Chloroform- $d$ ) $\delta 7.94(\mathrm{~d}, J=7.8 \mathrm{~Hz}, 1 \mathrm{H}), 7.69$ (t, $\left.J=7.5 \mathrm{~Hz}, 1 \mathrm{H}\right), 7.55$ (dt, $J=7.3,3.5 \mathrm{~Hz}, 2 \mathrm{H}), 7.28-7.26(\mathrm{~m}, 4 \mathrm{H}), 6.87-6.85(\mathrm{~m}, 4 \mathrm{H}), 3.79(\mathrm{~s}, 6 \mathrm{H}) .{ }^{13} \mathrm{C}$ NMR $(201$ $\left.\mathrm{MHz}, \mathrm{CDCl}_{3}\right) \delta 169.90,159.65,152.63,134.13,133.11,129.21,128.55,125.92,125.56,124.02$, 113.76, 91.67, 55.31. HRMS (m/z, ESI): calcd for $\mathrm{C}_{22} \mathrm{H}_{19} \mathrm{O}_{4}(\mathrm{M}+\mathrm{H})^{+}: 347.1278$. Found: 347.1284 .

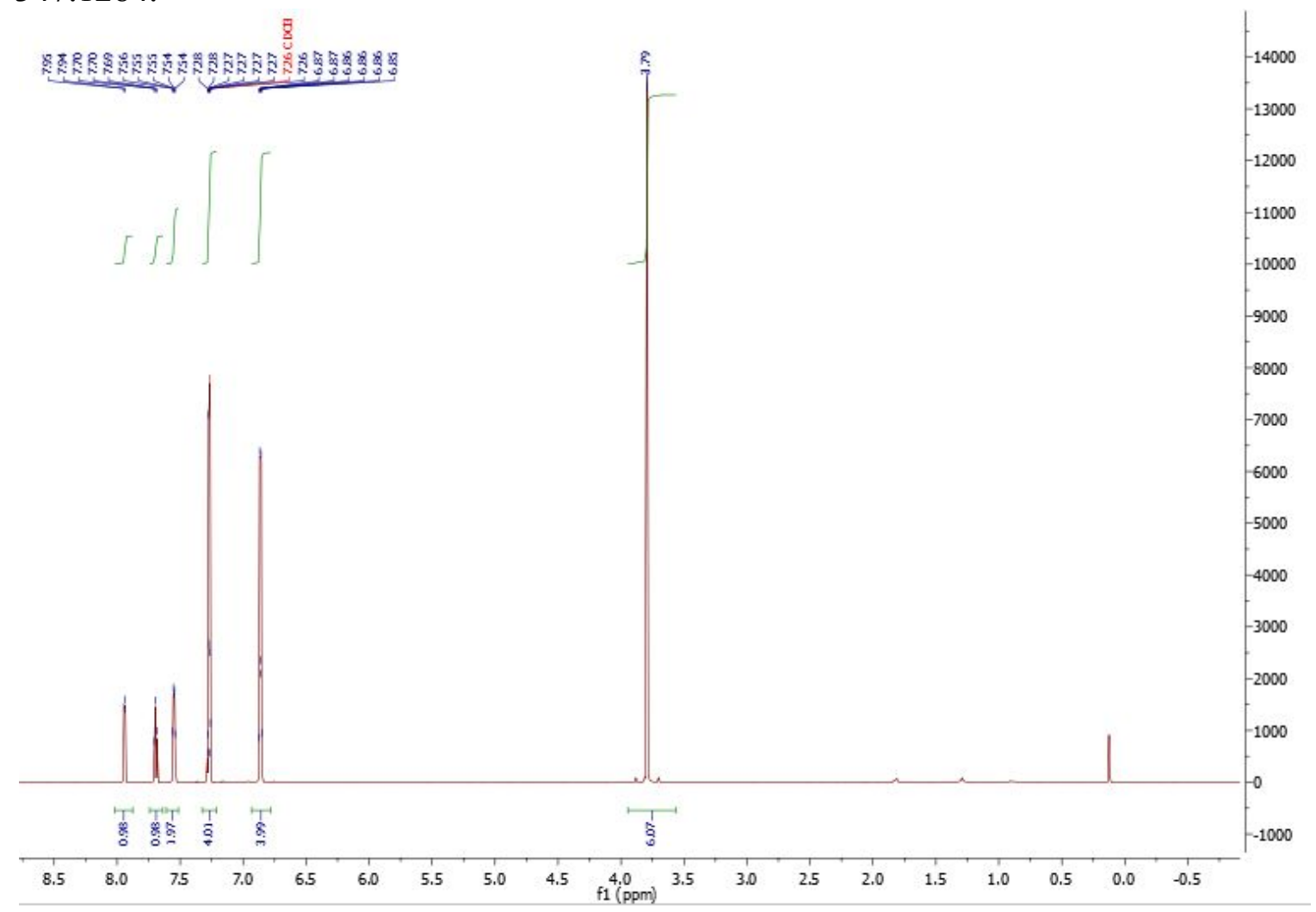


Figure 1S. $\quad{ }^{1}$ H NMR for 3,3-bis(4-methoxyphenyl)isobenzofuran-1(3H)-one (Me-PHPH).

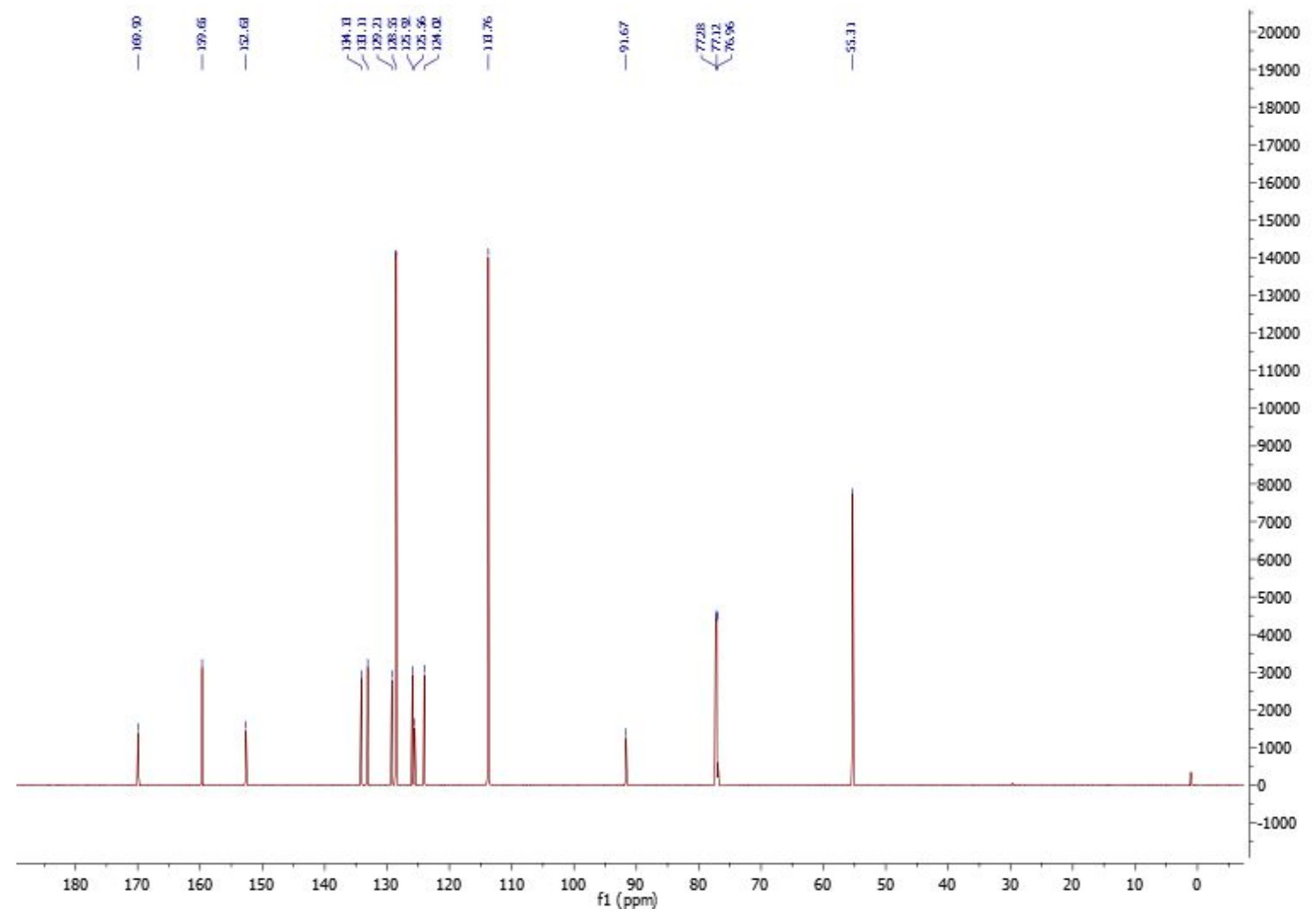

Figure 2S. $\quad{ }^{13} \mathrm{C}$ NMR for 3,3-bis(4-methoxyphenyl)isobenzofuran-1(3H)-one (Me-PHPH). 

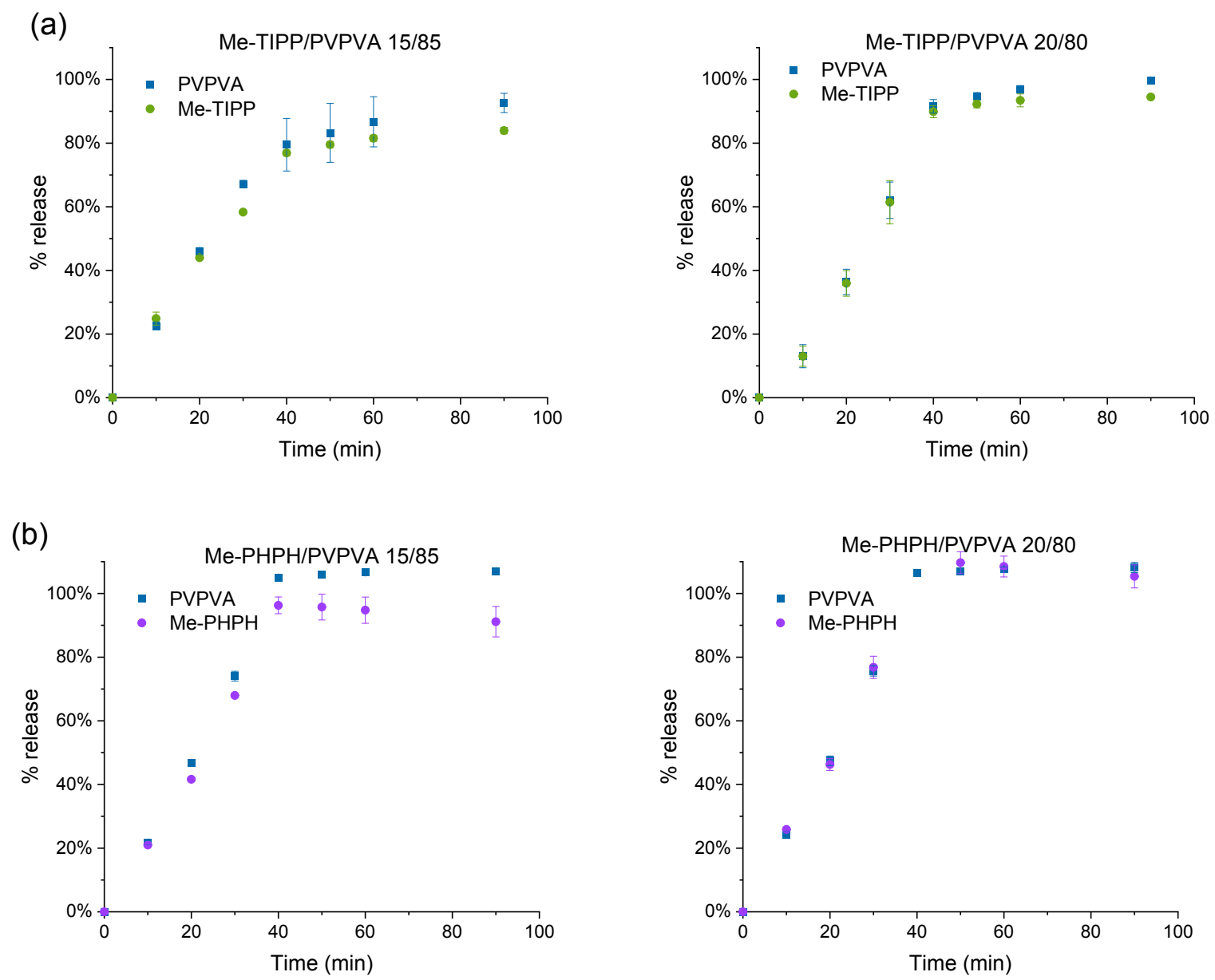

Figure 3S. Release profiles of (a) Me-TIPP/PVPVA ASDs with drug loading of 15 and $20 \%$, (b) Me-PHPH/PVPVA ASDs with drug loading of 15 and $20 \%$. 

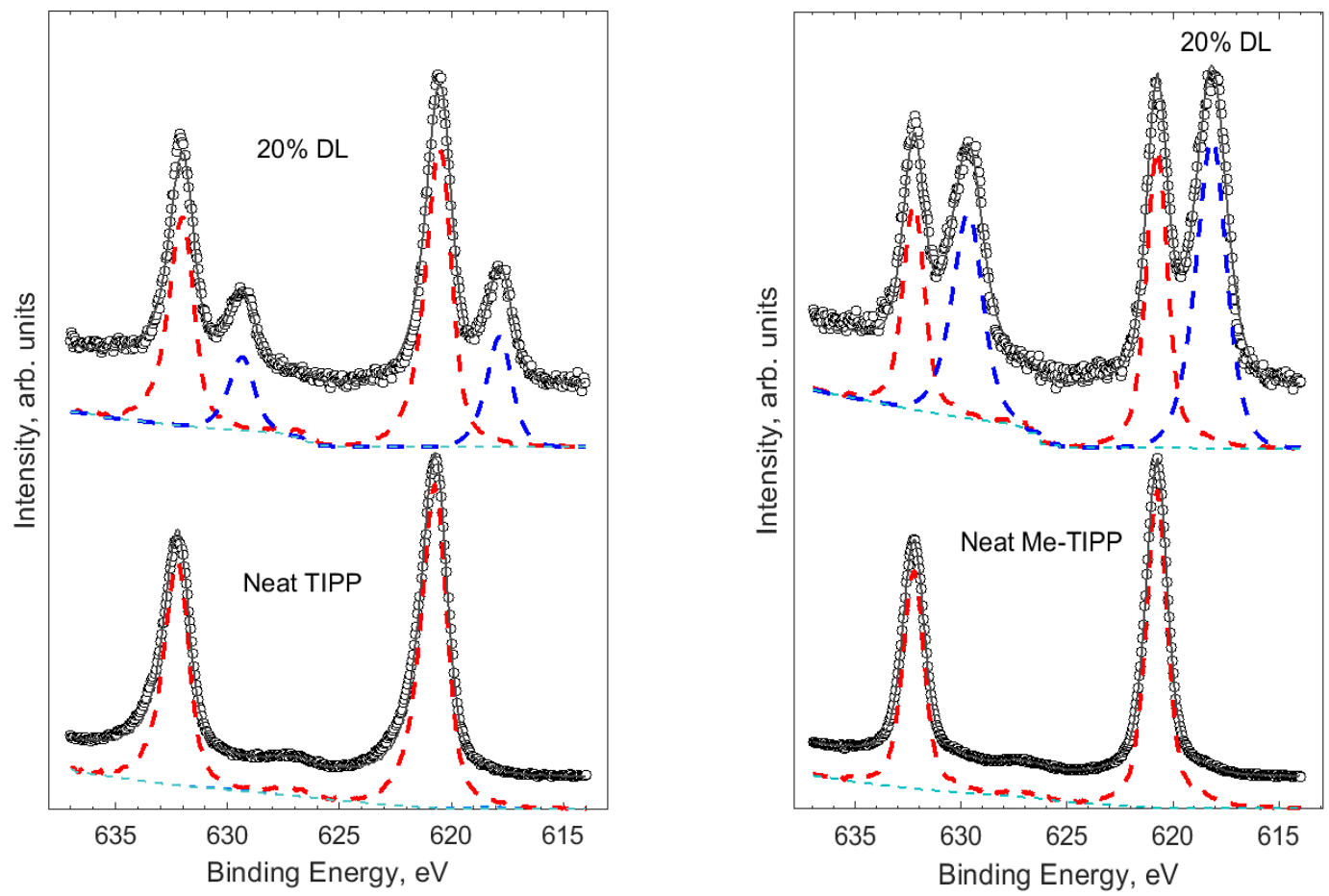

Figure 4S. Representative Iodo 3d X-ray photoelectron spectrum for (a) TIPP/PVPVA ASDs, (b) Me-TIPP/PVPVA ASDs. The open circles represent the cumulative spectra; the red dotted line represents the contribution from the neat drug; the blue dotted line represents the contribution from the electron rich iodine atoms; and the teal dotted line represents the background correction.

Table 1S. Atomic percentage of I atoms at the lower binding energy at different drug loadings for TIPP and Me-TIPP (Mean \pm STDEV).

\begin{tabular}{lcc}
\hline \hline Drug Loading & Me-TIPP & TIPP \\
\hline $10 \%$ DL & $60.8 \pm 4.1$ & $55.9 \pm 3.2$ \\
$20 \%$ DL & $53.3 \pm 5.1$ & $26.5 \pm 2.4$ \\
$30 \%$ DL & $29.9 \pm 1.6$ & $15.6 \pm 1.4$ \\
$40 \%$ DL & $22.2 \pm 1.5$ & $8.9 \pm 1.8$ \\
\hline \hline
\end{tabular}




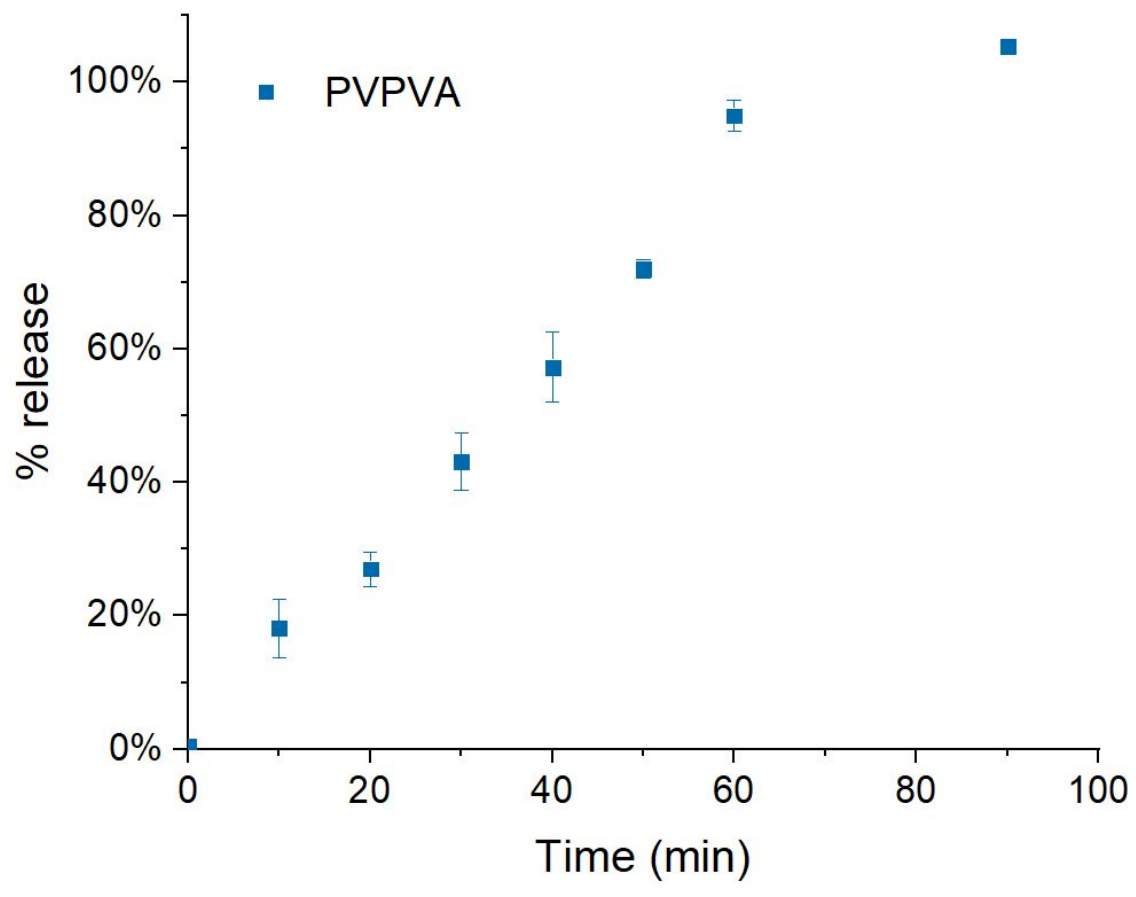

Figure 5S. Dissolution of neat PVPVA in pH 6.8 50mM phosphate buffer using an intrinsic dissolution apparatus with a surface area of $0.5 \mathrm{~cm}^{2}$.

Table 2S. Glass transition temperatures of ASDs used in the dissolution experiments.

\begin{tabular}{lcc}
\hline \hline ASD & Drug Load $(\% \mathrm{w} / \mathrm{w})$ & $\operatorname{Tg}\left({ }^{\circ} \mathrm{C}\right)$ \\
\hline \multirow{2}{*}{ TIPP/PVPVA } & 10 & $98.0 \pm 1.6$ \\
& 15 & $96.8 \pm 2.3$ \\
& 20 & $96.6 \pm 2.1$ \\
Me-TIPP/PVPVA & 20 & $98.0 \pm 2.0$ \\
& 30 & $97.1 \pm 2.7$ \\
PHPH/PVPVA & 50 & $100.2 \pm 2.0$ \\
& 10 & $108.3 \pm 0.2$ \\
Me-PHPH/PVPVA & 15 & $95.9 \pm 2.6$ \\
& 20 & $85.5 \pm 0.1$ \\
\hline \hline
\end{tabular}


(a)
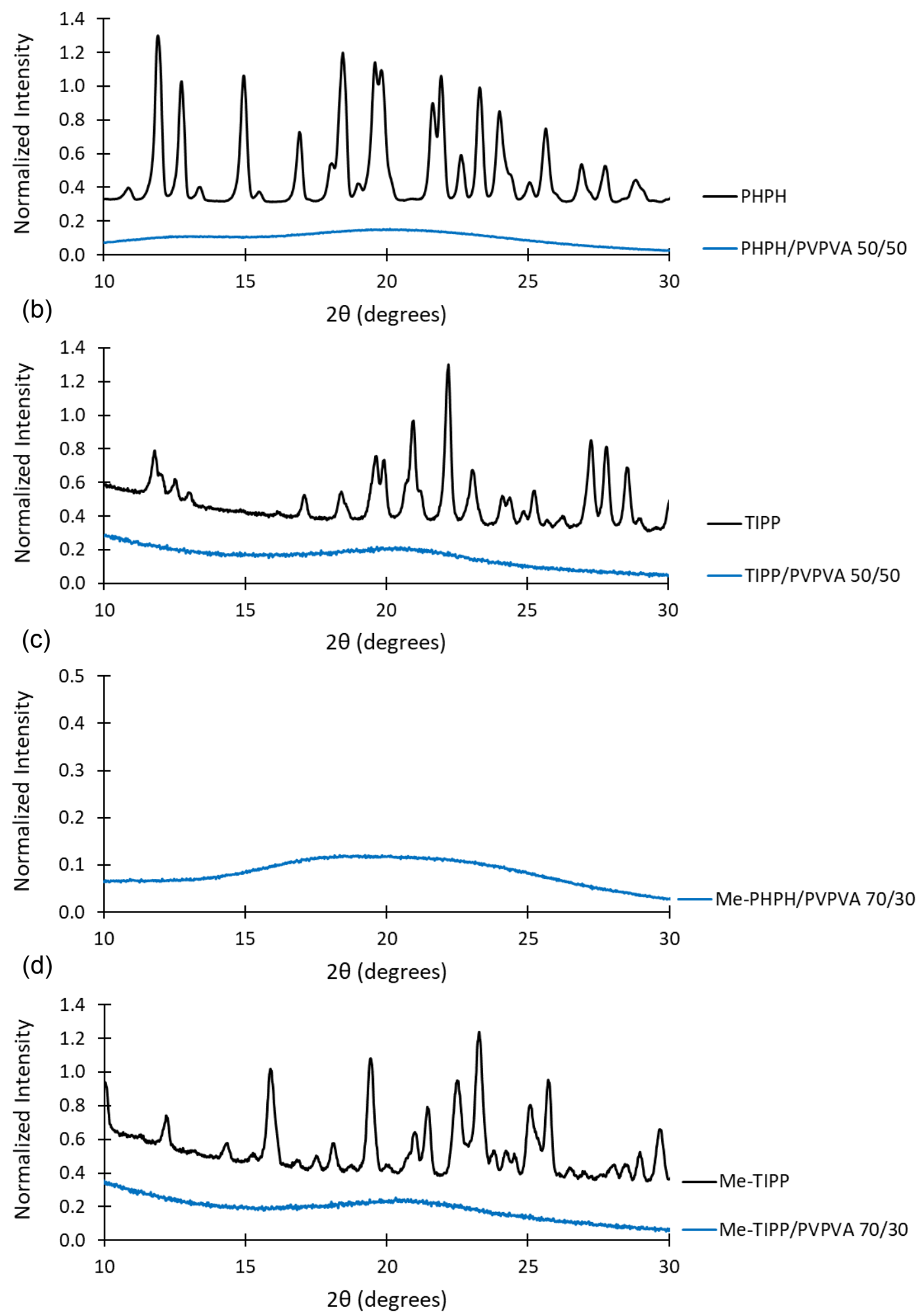

Figure 6S. X-ray powder diffraction patterns of neat crystalline model compounds and corresponding PVPVA-based ASDs for a) PHPH, b) TIPP, c) Me-PHPH, and d) Me-TIPP. Note that Me-PHPH is a viscous liquid at room temperature, therefore a diffraction pattern for the neat compound was not collected. 